\title{
Flexibilização das normas trabalhistas e a integridade física do trabalhador como aspecto fundamental da personalidade
}

\author{
Easing of labor standards and worker's physical integrity as a fundamental aspect of \\ personality Paper title in English
}

Heloísa Alva Cortez Gonçalves ${ }^{1}$

\begin{abstract}
Resumo
O presente artigo tem como escopo, analisar os direitos de personalidade do indivíduo como empregado, relacionando-o ao stress ocupacional que pode ameaçar a sua integridade física. Primeiramente abordou-se um estudo sobre o direito da personalidade e o princípio da dignidade da pessoa humana e a flexibilidade das normas trabalhistas, e posteriormente foi abordado conceitos acerca do stress e stress ocupacional. Em seguida analisou-se o stress ocupacional a luz do direito da integridade física, no qual foi possível verificar que o empregado necessita de um ambiente de trabalho que preserve a vida, com dignidade humana, a fim de evitar danos a sua integridade física. Buscou-se ilustrar os danos causados ao empregado, no que tange ao stress ocupacional, com um processo ocorrido entre a Caixa Econômica Federal de Maceió e um ex-empregado.
\end{abstract}

Palavras Chave: Direito de personalidade; Integridade física, Stress ocupacional.

\begin{abstract}
The scope of this article is to analyze the personality rights of the individual as an employee, relating to the occupational stress that can threaten their physical integrity. First we dealt with a study on the right personality and the principle of human dignity and the flexibility of labor standards, and then was approached about the concepts of stress and occupational stress. Then we analyzed the light of occupational stress right limb, in which it was possible to verify that the employee needs a work environment that preserves life, with dignity, to avoid damage to their physical integrity. We sought to illustrate the damage caused to the employee, in relation to occupational stress, with a process that took place between the Federal Savings Bank of Miami and a former employee.
\end{abstract}

\footnotetext{
1 Possui graduação em Direito (2007), pós-graduação em Direito Público pela Universidade Gama Filho.- RJ (2008), especialista em Direito Ambiental pela Universidade Internacional de Curitiba -PR (2011), Mestrado em DIreito pelo Centro Universitário de Maringá (2011), pós graduanda em Direito Constitucional pela Universidade Estadual de Maringá - UEM (2010). Atualmente é professora titular da graduação da Faculdade do Noroeste Paranaense (FANP), e professora da graduação da Faculdade Alvorada. Tem experiência e atuação profissional de pesquisa na área Trabalhista, e Constitucional. Atua como advogada na região. Contato: heloisa.cortez@fanp.com.br.
} 
Keywords: Right of Personality; Integrity Physical; Occupational Stress.

\section{Introdução}

O ser humano pressupõe, em sua formação, a satisfação de suas necessidades engajadas aos direitos fundamentais, entre os quais se situam os que se manifestam através dos direitos da personalidade.

O indivíduo passa por diversos momentos, seja na família, escola, comunidade e pelo ambiente de trabalho, no qual consome parte considerável de sua vida. Assim ele vive uma complexidade de relações interpessoais que afetam sua personalidade mais do que qualquer outro ambiente, e, em conseqüência, as relações que se desenvolvem fora desse espaço social ímpar.

Sendo assim, é fundamental um ambiente sadio em todos os aspectos, garantindo ao trabalhador uma existência digna conforme os pareceres da justiça social. Caso contrário, pode levar o trabalhador a insatisfação no trabalho, na qual se traduz por depressão e hostilidade para enfrentar o dia a dia, gerando o stress.

O stress ameaça a integridade física e emocional do indivíduo. Com freqüência, a ansiedade pode estimular o indivíduo a tomar decisões e providências, bem como ocupar-se de atividades práticas, tentando achar a chave para seu problema, porém, podem surgir dificuldades quando não encontra a solução, ou sua ansiedade é desproporcional às circunstâncias.

Neste contexto, o objetivo deste estudo é analisar os direitos de personalidade do indivíduo como empregado, relacionando-o ao stress ocupacional que pode ameaçar a sua integridade física.

\section{Direitos da personalidade e o princípio da dignidade da pessoa humana}

Os direitos da persolidade estão vinculados ao reconhecimento de valores inerentes à pessoa humana, e são imprescindíveis ao desenvolvimento de suas potencialidades físicas, psíquicas e morais. Adriano de Cupis (2006, p. 15), afirma que:

"[...] todos os direitos, na medida em que conferem conteúdo à personalidade, poderiam chamar-se direitos da personalidade. No entanto, na linguagem jurídica 
corrente, essa designação é reservada àqueles direitos subjetivos, cuja função, relativamente à personalidade, é especial, constituindo o 'minimum' necessário e imprescindível ao seu conteúdo. Por outras palavras, existem certos direitos sem os quais a personalidade restaria uma susceptibilidade completamente irrealizada, privada de todo o valor concreto: direitos sem os quais todos os outros direitos subjetivos perderiam todo o interesse para o indivíduo - o que equivale a dizer que, se eles não existissem, a pessoa não existiria como tal."

Para Amauri Mascaro Nascimento (1997, p. 481), “Direitos de personalidade são aqueles de natureza extra patrimonial que se referem aos atributos essenciais definidores da pessoa, e dentre todos os direitos são aqueles que mais de perto procuram valorizar a dignidade do ser humano".

Pode-se dizer que os bens da personalidade se referem à essência do ser humano, e conseqüentemente, o direito da personalidade vem para proteger estes bens, para dar existência digna à pessoa. Nesta visão Capelo de Souza (2008, p. 15) afirma que a personalidade é um complexo de características interiores com o qual o indivíduo pode manifestar-se perante a coletividade e o meio que o cerca, revelando seus atributos materiais e morais. Com efeito, no sentido jurídico, a personalidade é um bem, aliás, o primeiro pertencente à pessoa.

Assim, afirma-se que a dignidade humana é o objeto, ao final, tutelado pelos direitos da personalidade. Não há consenso doutrinário a respeito da origem histórica dos direitos da personalidade. Para alguns, foi na Idade Média que o homem, cultuando a espiritualidade por meio de uma busca interior, tomou consciência da personalidade e necessidade de sua tutela. Há quem situe a gênese de tais direitos na antiguidade com as dike kakegorias, na Grécia e a actio injuriarum, em Roma. Rita de Cássia Curvo Leite (2006, p. 29) afirma que:

\footnotetext{
“a consciência ôntica e ética do homem como personalidade é algo desconhecido no mundo antigo greco-romano. A antiguidade e sobretudo os gregos viam a essência do homem no que poderíamos chamar de humanitas, vale dizer, no ser político, no viver politicamente. $O$ sentimento que envolve a personalidade e a estima de seu valor moral, a consciência que o homem ocidental tem acerca de seu próprio ser como um fim em si mesmo, como um centro autônomo de intimidade e de vida, foi algo ignorado pelo homem antigo"
}

De acordo com Maria Helena Diniz (2006, p. 456), a origem dos direitos da personalidade ocorreu após a Segunda Guerra Mundial. Diante das agressões causadas pelos 
governos totalitários à dignidade humana, tomou-se consciência da importância dos direitos da personalidade resguardando-os na Assembléia Geral da ONU de 1948, na Convenção Européia de 1950 e no Pacto Internacional das Nações Unidas. Renan Lotufo (2005, p. 387) diz que foi, portanto, com a Declaração Universal dos Direitos Humanos que, de fato, os direitos da personalidade tiveram destaque.

Capelo de Souza (2008, p. 483) complementa dizendo que com a aceleração do desenvolvimento tecnológico pós-guerra, ou seja, com a tensão causada pelo desenvolvimento, o homem passa a reivindicar um espaço seu, ou melhor, um direito que contemple a especificidade de sua personalidade. Isso não ocorre com a retomada de concepção individualista ou liberal, mas com a exaltação de uma visão personalista e ética de formação e desenvolvimento do ordenamento jurídico.

Antonio Bento Betioli (2004, p. 15) afirma que os direitos da personalidade tutelam a integridade do ser humano. Há, para análise da proteção da personalidade, uma tripartição da personalidade nas respectivas: integridade física, compreendendo: vida, alimentos, próprio corpo (vivo ou morto), corpo alheio e partes separadas do corpo; integridade intelectual, compreendendo: liberdade de pensamento, autoria científica, literária e artística e, por fim; integridade moral, compreendendo: honra, segredo profissional, segredo doméstico, direito de autor, identidade familiar, pessoal e social.

Atualmente, a proteção da dignidade da pessoa humana, prevista na Constituição Federal Brasileira, artigo 1ำ, III, tornou-se necessária, pois se protege a honra, a reputação, a imagem, o nome e os atributos humanos, a afetividade, a sexualidade, a integridade física e psíquica, todos os fatores fisiológicos, psicológicos e emocionais decisivos para a felicidade e o bem estar do homem. É indispensável proteger a saúde e a integridade física no trabalho, cercando o trabalhador de garantias mínimas, sendo a sua preservação necessária para que o mesmo possa crescer fisicamente, culturalmente e psicologicamente como pessoa digna. (MELLER, 2007, p. 187).

Edwin Krautler e Ivan Dias da Motta (2006, p. 506-509) justificam que mesmo com o poder nas mãos do Estado, em relação aos direitos trabalhistas, e com as intenções de bem comum, se os direitos de personalidade do trabalhador vierem a ser ofendidos, levará a graves conseqüências: "podem oferecer uma tendência ao esmagamento do ser humano, é na esteira de tais balizamentos que se haverão de entender os direitos da personalidade, 
mormente no âmbito do direito do trabalho, já que tais direitos, muitas vezes, sucumbem aos interesses econômicos."

Analisa-se também, na Constituição Federal Brasileira, sobre o "ambiente ecologicamente equilibrado", em seu art. 225, o que a doutrina entende é que se estende ao ambiente de trabalho, sem contar que a Organização Internacional do Trabalho, ao usar a expressão "emprego decente", na Recomendação 193, o faz com a conotação de que o trabalho seja decente, em todos os seus aspectos, inclusive, do meio ambiente digno ao trabalhar.

Neste contexto, verifica-se que o ambiente de trabalho equilibrado, promove o direito da dignidade da pessoa humana. Raimundo Simão de Melo citado por Leda Maria Messias da Silva (2008, p. 202) expõe que o bem ambiental envolve a vida do trabalhador e cabe ao empregador, primeiramente, a obrigação de "preservar e proteger o meio ambiente laboral e, ao Estado e à sociedade, fazer valer a incolumidade desse bem".

Portanto, ter um meio-ambiente de trabalho sadio é um direito do empregado, tal como, é um dever do empregador, garantir esse meio-ambiente de trabalho sadio. É o empregador quem detém o poder diretivo que se manifesta através do "Poder de Organização do seu empreendimento", do "Poder de Disciplinar", advertindo, suspendendo e até rescindindo o contrato, quando houver um motivo justo, como pode ser o caso de um empregado que lese um direito de personalidade de outro. E, ainda, detém o "Poder de Controle", fiscalizando o ambiente de trabalho, de forma adequada, com razoabilidade, a fim de garantir um ambiente "ecologicamente equilibrado" (2008, p. 202).

A finalidade de todos esses cuidados e exigência, conforme Leda Maria Messias da Silva e Lory Kurahashi (2008. p. 105), é: integridade física e mental do empregado, que é um direito de personalidade do mesmo.

Leda Maria Messias da Silva (2008, p. 105) afirma que uma situação comum que pode acontecer no ambiente de trabalho é a pressão psicológica. Segundo a autora:

\footnotetext{
"Outrossim, o ambiente onde o trabalhador passa a maior parte de sua vida útil, sabe se, muitas vezes, passa a ser um pesadelo na vida do trabalhador, pois neste ambiente pode sofrer verdadeiras torturas psicológicas, em decorrência do comportamento inadequado, ora do empregador, de um preposto ou mesmo de um colega de trabalho e até de um subordinado. $O$ assunto é tão sério, que no aspecto psíquico, por exemplo, a degradação do ambiente pode, muitas vezes levar ao suicídio, como não raro se ouve falar, nos casos de empregados que sofrem
} 
assédio moral no ambiente de trabalho, e que em situações mais críticas perdem o interesse não só pelo trabalho, mas pela vida."

Umas das conseqüências do descaso com tais fatos são empregados mais adoentados e com precoce aposentadoria, sem olvidar das lesões aos direitos da personalidade do empregado, que podem gerar indenizações por danos morais. O local de trabalho não pode fazer mal ao empregado, por isso os direitos da personalidade, devem ser resguardados (Idem op. cit. p. 103).

Hoje, verifica-se que a prática do meio ambiente de trabalho só estará mais próxima do ambiente decente, equilibrado e, portanto, digno se o empregado, parte economicamente mais fraca, estiver respaldado por uma razoável superioridade jurídica. Essa superioridade jurídica frente ao empregador proporciona o equilíbrio de uma relação desigual. Esse equilíbrio somente pode ser assegurado, quando existem mecanismos jurídicos que respaldam a dignidade do trabalhador (SILVA, 2008, p. 203).

\section{Flexibilidade das normas trabalhistas}

É notório que o direito do trabalho é um ramo da ciência jurídica extremamente ativo e dinâmico, altamente ligado às instabilidades políticas, motivo pelo qual sempre se altera para melhor solucionar os problemas relacionados ao capital e ao trabalho. E, nesses panoramas de instabilidades, é que surgiu a denominada teoria da flexibilização das normas trabalhistas. Esse dinamismo inerente ao direito laboral ocorre justamente para adequá-lo, com maior facilidade, à realidade social em que se encontra determinado país, auxiliando-o, por exemplo, na sua reestruturação e recuperação frete aos adventos das crises.

Nesse contexto, o Brasil, com a crise do petróleo ocorrida em 1973 na Europa precisou rever algumas leis trabalhistas, o que resultou na diminuição do rigor das mesmas. O objetivo visado com referida medida foi à preservação das relações econômicas e sociais. Portanto, certas regras de flexibilização do direito do trabalho podem ser instituídas tanto in mellius (para melhorar as condições de trabalho), como in peius (para piorar as condições de trabalho, entendidas como tal o aumento da jornada de trabalho, bem como a redução de salários, entre outros).

Dessa forma, frente à terceira revolução industrial, chamada de revolução tecnológica, as relações trabalhistas precisaram ser adaptadas à nova realidade social a fim 
de barrar o desemprego estrutural crescente e, conseqüentemente, preservar a Política Social, entendida esta como um bem maior a ser preservado, na medida em que se dirige ao bem estar de todos os cidadãos, ao bem estar coletivo.

Sendo assim, surge o fenômeno da globalização dos mercados, e as pressões em torno da flexibilização das normas trabalhistas ganham forças. Vive o mundo sofrendo profundas modificações nas relações trabalhistas, falando-se, em todos os quadrantes, em flexibilizar as relações, por isso que, quando se cogita em flexibilizar vincula-se à necessidade de conceder às regras obreiras maior plasticidade, maleabilidade, destituído da rigidez tradicional.

A teoria da flexibilização da legislação trabalhista surgiu com o fulcro de abarcar a dinamicidade do direito laboral e lidar com a luta entre o capital e o trabalho. Segundo Sérgio Pinto Martins (2002, p. 507): “As causas da flexibilização compreendem vários fatores: a) desenvolvimento econômico; b) globalização; c) crises econômicas; d) mudanças tecnológicas; e) encargos sociais; f) aumento do desemprego; g) aspectos culturais; h) economia informal; i) aspectos sociológicos".

A flexibilização das normas trabalhistas, conforme afirma Amauri Mascaro Nascimento ${ }^{2}$, não prejudica a função protetora do Direito do Trabalho, uma vez que direitos como os da personalidade não são atacados por esta nova tendência, pois esta protação ao trabalhador está constitucionalmente garantida através do princípio da dignidade humana, sendo que estes valores se sobrepõe ao plano contratual.

Para conceituar a flexibilidade das normas trabalhistas é necessário entender o significado de flexibilização no contexto das relações de trabalho. Sérgio Pinto Martins (2002, p. 508) conceitua a flexibilização como "um conjunto de regras que tem por objetivo instituir mecanismos tendentes a compatibilizar mudanças de ordem econômica, tecnológica ou social existentes na relação entre o capital e o trabalho".

Arnaldo Süssekind (2001, p. 480), complementa dizendo que a flexibilização envolve aspectos que influenciam diretamente no protecionismo estatal diante do empregado. Tal ponto de vista também é observado pelos detentores do capital, que buscam a diminuição do custo de produção para concorrer ao mercado globalizado. A desregulamentação retira a

\footnotetext{
${ }^{2}$ Citado por MELLER, Fernanda; SILVA, Gilson Hugo Rodrigo. A flexibilização das normas trabalhistas como uma tendência atual e a integridade física do trabalhador como aspecto fundamental da personalidade. Revista de Ciências Jurídicas - UEM. v.5, n.1, jan/jun 2007. p. 188.
} 
proteção Estatal ao trabalhador, permitindo que a autonomia privada, individual ou coletiva, regule as condições de trabalho.

O mesmo autor conceitua a flexibilização do direito do trabalho, dizendo que consiste numa ampliação na capacidade e no poder das partes envolvidas no contrato de trabalho, tanto o empregador como o empregado, em estabelecerem e definirem os parâmetros e limites que regerão as suas relações de trabalho.

Sendo assim, a flexibilização das condições de trabalho resulta na redução de direitos trabalhistas, mediante negociação coletiva, com o objetivo de diminuir custos e possibilitar ao empregador transpor períodos de crise nos quais a continuidade da atividade empresarial e a manutenção de postos de trabalho são os bens maiores a defender (LOPES, 2002. p. 10-19).

A flexibilização possui o intuito de adaptar a legislação trabalhista a uma perspectiva global, sendo que esta por sua vez está intimamente conectada a uma ideologia neoliberal.

A Constituição da República Federativa do Brasil, em seu artigo 1.ํ, ao tratar dos fundamentos do "Estado Democrático de Direito", defende a "Dignidade da Pessoa Humana". Isso quer dizer, que deixar para o setor privado definir as regras do contrato de trabalho pode implicar em uma liberação de contratos de trabalho com objetos demasiadamente cruéis, em desacordo com os fundamentos do Brasil.

Segundo Arnaldo Süssekind (2001, p. 481), os defensores do Estado Social admitem a redução do grau de intervenção da lei, desde que para isso os sistemas legais constituam regras gerais indisponíveis. Isso para ser garantido o mínimo de proteção a todos os trabalhadores, sendo-lhes garantida a dignidade do ser humano, o atendimento às peculiaridades regionais, implantação de novas tecnologias e métodos e, também, preservação da saúde econômica da empresa e do empregado.

Analisando a flexibilização perante a Constituição Federal, segundo Edivaldo Nilo de Almeida (2004, p. 450-466), verifica-se que as possibilidades de flexibilização são encontradas no artigo 7으, incisos VI, XIII e XIV:

“O art. 70 a Constituição Federal, em sua parte final, dispõe que as novas leis trabalhistas devem contribuir para a melhoria da condição social do empregado. Todos os direitos trabalhistas estabelecidos no texto constitucional são garantias mínimas e deve-se buscar ao máximo a melhoria de condição de vida do 
trabalhador. O postulado normativo da norma mais favorável ao obreiro está implícito neste artigo. Na interpretação de conflitantes normas de direito do trabalho, os juristas (latu sensu) devem aplicar aquela que mais favorecer ao empregado (salvo as exceções previstas nos artigos 70, VI, XIII e XIV da Carta Magna)."

O mesmo autor afirma que fazendo uma interpretação teleológica, pode-se dizer também que a Constituição, no seu art. 7ํㅡ, proíbe que as condições mais vantajosas e conquistadas pelo empregado sejam modificadas para pior. Esse princípio só deve ser ponderado nos casos de estado de defesa e estado de sítio, isto é, somente nas hipóteses previstas nos artigos 136, caput, e 137 da CF/88. Desse modo, em momentos de normalidades constitucionais, qualquer emenda constitucional ou qualquer lei que não gere uma melhoria social para o trabalhador é inconstitucional.

Arnaldo Süssekind (2001, p. 480) complementa esclarecendo que as normas constitucionais trabalhistas só podem ser flexibilizadas em três hipóteses: "A Constituição brasileira de 5 de outubro de 1988 possibilitou a flexibilização de algumas de suas normas: redutibilidade salarial, compensação de horários e trabalho noturnos de revezamento (art. 7ㅇ, VI, XIII e XIV); mas sempre sob a tutela sindical."

Acerca da flexibilização permitida pela Constituição, Priscila Campana (2000, p. 129-144) lembra:

\footnotetext{
“Como a crise do Estado social é acompanhada pela tendência à flexibilização no Direito do Trabalho, não é de hoje que existem as flexibilizações legalmente instituídas, [...] o ordenamento jurídico constitucional traz alguns dispositivos com clara inspiração flexibilizadora: o art. 70, VI [...], XIII e XIV[...] em países que desregulamentaram o mercado de trabalho, como a Argentina e Espanha, as taxas de desemprego estão atualmente entre as mais elevadas - respectivamente, $29 \%$ e $24 \%[\ldots] . "$
}

Para a autora, a flexibilização dos direitos sociais, é mais um mecanismo capitalista de manutenção do sistema de exploração e aferição de lucros às empresas e conglomerados econômicos. Flexibiliza-se para a manutenção da mais valia, para o controle da taxa de lucro. Quanto menos "encargos sociais" tiver o capitalista, quanto menos gastar com o trabalhador, melhor gerencia seus interesses na busca por acumulação de capital. 
Neste contexto, verifica-se que o tema flexibilização das normas trabalhistas é polêmico. Fernanda Meller e Gilson Hugo Rodrigo Silva ${ }^{3}$ afirmam que os autores Luiz Carlos Amorim Robortella, Octavio Bueno Magano, Amuri Mascaro Nascimento, José Pastore e Rosita de Nazaré Sidrim Nassar, defendem a flexibilização. Eles afirmam que esses autores argumentam que os avanços das conquistas trabalhistas tornaram-se excessivamente onerosas para as empresas e isto provoca inevitáveis cortes de pessoal e como conseqüência o desemprego. Defendem ainda a substituição do sistema atual, com o objetivo de permitir a prevalência do processo negocial sobre o processo estatal de formação das normas jurídicas, ou seja, o negociado prevalecendo sobre o legislado.

\section{Integridade física - stress}

\section{Conceitos acerca do stress e stress Ocupacional}

O mundo contemporâneo é muito diferente dos ambientes de épocas primitivas da história da humanidade. Todavia, os processos fisiológicos por que passam os organismos humanos mudaram muito pouco desde então e ainda são programados biologicamente para conviver com lugares primitivos e perigosos. Por este motivo, afirma-se que o ser humano sofre por viver na era espacial com uma constituição da Idade da Pedra. Para corroborar com esta afirmação, diversas pesquisas demonstraram que em situação de perigo as pessoas apresentam reações muito parecidas com as que os animais manifestam quanto ameaçados. A esse fenômeno biológico foi dado o nome de stress, palavra que vinha sendo utilizada nas ciências exatas para designar o total de forças que agem contra uma resistência. Para o organismo biológico o stress é uma resposta não específica a eventos que the são impostos (ALVES, 1992, p. 10).

Segundo Cabral ${ }^{4}$ (2001), o stress é causado por agentes estressores, que pode ser qualquer estímulo capaz de provocar o aparecimento de um conjunto de respostas orgânicas ou psicológicas.

\footnotetext{
${ }^{3}$ Citado MELLER, Fernanda; SILVA, Gilson Hugo Rodrigo. A flexibilização das normas trabalhistas como uma tendência atual e a integridade física do trabalhador como aspecto fundamental da personalidade. Revista de Ciências Jurídicas - UEM. v.5, n.1, jan/jun 2007. p. 192.

${ }^{4}$ Disponível em: http://www.icb.ufmg.br/Ipf. Acesso em: 04 de out. 2007. p. 8.
} 
Sobre o stress ocupacional, Tatiane Paschoal e Álvaro Tamayo ${ }^{5}$ afirmam que tem crescimento pesquisas nesta área, e isto deve-se ao impacto negativo que este fenômeno tem no funcionamento e na efetividade das organizações, tendo como marco a constatação do aparecimento de doenças vinculadas ao trabalho e a necessidade das organizações de desenvolverem ações de prevenção dessas doenças, uma vez que pessoas stressadas diminuem seu desempenho e aumentam os custos das organizações com problemas de saúde, absenteísmo, rotatividade e acidentes no local de trabalho, além de afetar a integridade física da pessoa.

Nos dias atuais, é freqüente no ambiente organizacional a cultura, o clima, seus valores e ritos, a rigidez das normas, a divisão do trabalho, o excesso de hierarquização, a falta de autonomia, a crescente competição, a exigência para o desenvolvimento de novas competências, a necessidade de trazer maiores resultados e lucros para a organização levam as pessoas, muitas vezes, ao limite de suas resistências físicas e psicológicas. Dessa forma, quando a demanda do trabalho excede as habilidades da pessoa e ela não consegue mais superar ou se adaptar às exigências da organização, percebidas como insuperáveis, pode surgir um desgaste anormal ou uma diminuição da capacidade da pessoa para o trabalho.

De acordo com Ana Magnólia Mendes e Álvaro Tamayo ${ }^{6}$, o stress ocupacional é analisado sob vários prismas, entre eles as condições de trabalho, as condições externas ao trabalho e as características da pessoa. Destacam-se as seguintes variáveis quanto às condições de trabalho: plano de carreira insatisfatório, falta de autonomia, segurança, estilo da liderança, políticas internas de gestão de pessoas, relacionamento interpessoal, prazos para entrega de produtos e serviços, ritmo de trabalho, excesso de atividades, novas tecnologias, além de aspectos de salubridade como limpeza, ruídos, ventilação.

Segundo Villalobos(1999, p. 8$)^{7}$, os fatores psicossociais no trabalho que podem levar ao desenvolvimento de stress nas pessoas são relativos ao desempenho profissional, ao estilo gerencial, à organização do trabalho, às tarefas e atividades, ao meio ambiente do trabalho, à jornada laboral e ao contexto social em que a organização está inserida.

No que concerne ao desempenho profissional, o mesmo autor destaca variáveis como complexidade das atividades; excesso de responsabilidade; criatividade e iniciativa

\footnotetext{
${ }^{5}$ Disponível em: http://www.scielo.br/pdf/epsic/v9n1/22380.pdf. Acesso em: 20 dez. 2010.

${ }^{6}$ Disponível em: http://www.scielo-psi.bvs.br. Acesso em: 28 set. 2007.

${ }^{7}$ Disponível: <http://www.medspain.com/n3_feb99/stress.htm> Acesso em: 22 nov. 2010.
} 
restringidas; exigência de decisões complexas e mudanças tecnológicas. No fator referente ao estilo gerencial o autor dá ênfase à má utilização das habilidades das pessoas; à ineficiência na delegação de responsabilidades; à forma manipulativa de relacionar-se com o subordinado, à falta de capacitação e desenvolvimento do pessoal; à carência de reconhecimento e incentivos e à remuneração não eqüitativa.

O estresse ocupacional pode ser dividido em três aspectos: a) estressores organizacionais do ambiente do trabalho que exige respostas adaptativas; b) respostas fisiológicas, psicológicas e comportamentais que as pessoas têm quando expostos a fatores do trabalho que excedem sua capacidade adaptativa e de enfrentamento; c) processo geral em que demandas de trabalho têm impacto nas pessoas que trabalham na organização.

$\mathrm{Na}$ concepção de Lazarus $^{8}$, o estresse ocupacional ocorre quando o indivíduo avalia as demandas do trabalho como excessivas para os recursos de enfrentamento que possui. Dessa forma, o surgimento do estresse ocupacional estaria intimamente ligado a um tipo particular de ambiente com um tipo determinado de pessoa.

Tatiane Paschoal e Alvaro Tamayo ${ }^{9}$ conceituam o stress ocupacional como um processo em que o indivíduo percebe demandas do trabalho como estressores, os quais, ao exceder sua habilidade de enfrentamento, provocam no sujeito reações negativas.

Neste contexto, há previsto na constituição e no código civil, leis que defendem a integridade física e o direito da personalidade do empregado.

\section{Direito a integridade física}

O direito à integridade física e psíquica constitui um paradigma de defesa da personalidade contra ameaças e agressões que se traduzam em lesões da integridade física e psíquica das pessoas. ${ }^{10}$

Por integridade psicofísica pode-se entender o direito a não sofrer violações em seu corpo ou em aspectos de sua personalidade. Incluídos estariam também os aspectos da vida

\footnotetext{
${ }^{8}$ Citado por PASCHOAL, Tatiane e TAMAYO, Alvaro. Validação da escala de estresse no trabalho. Universidade de Brasilia. São Paulo: Casa do Psicólogo. Estudos de Psicologia 2004, 9(1), 45-52. Disponível em <http://www.scielo.br/pdf/epsic/v9n1/22380.pdf.> Acesso em: 20 dez. 2010.

${ }^{9}$ Citado por PASCHOAL, Tatiane e TAMAYO, Alvaro. Validação da escala de estresse no trabalho. Universidade de Brasilia. São Paulo: Casa do Psicólogo. Estudos de Psicologia 2004, 9(1), 45-52. Disponível em <http://www.scielo.br/pdf/epsic/v9n1/22380.pdf.> Acesso em: 20 dez. 2010.

${ }^{10}$ LACERDA, Dennis Otte. Direito da Personalidade e integridade psicofísica. XVIII Congresso Nacional do CONPEDI, 2009, São Paulo. Anais... ISBN: 978-85-7840-029-3 p.5277.
} 
moderna, ligados especialmente a temas como saúde e biodireito. Proteção de dados genéticos, reprodução assistida, atos de disposição do próprio corpo, entre outros, são situações novas, merecedoras de tutela e que, entretanto, ainda não encontraram solução satisfatória em nosso direito. ${ }^{11}$

Não há razão para separar a defesa da integridade física da defesa contra ameaças e agressões à sua integridade psíquica. Não existe uma fronteira nítida entre a integridade física e a integridade psíquica, como bens da personalidade a defender, e mesmo muitas vezes as ameaças e agressões atingem necessariamente quer o físico quer o psíquico, ou atingem um através do outro. Embora possa também haver lesões da integridade física que não tenham seqüelas ou conseqüências na integridade psíquica e vice-versa, parece ser de englobar num único tipo de tutela da personalidade a integridade psicofísica. ${ }^{12}$

A integridade física e psíquica são postas em causa sempre que algo existe que as põe em perigo ou as ofende. A integridade física e psíquica são de uma vasta amplitude e abrangem a saúde em geral, quer a saúde física, quer a psíquica. O direito à integridade psicofísica tem por objeto a preservação da intocabilidade do corpo físico e mental da pessoa humana. ${ }^{13}$

Dennis Otte Lacerda ${ }^{14}$, afirma que o princípio da dignidade da pessoa humana impôs, num primeiro momento, limites à atividade estatal, uma vez que impede a violação, por qualquer dos poderes à atividade estatal, da integridade psicofísica de qualquer particular. Há que se lembrar, entretanto, que o direito à integridade psicofísica dispõe, também, de um caráter positivo, que consiste em uma série de situações que têm que ser garantidas pelo Estado a todos os seus membros, indistintamente. Tome-se, como exemplo o direito à saúde. Além de garantir a pessoa contra qualquer violação, por parte dele Estado ou de particulares, há o Estado que tomar uma série de medidas positivas no sentido da efetivação de tais direitos. Assim, o Estado há de implantar uma rede pública de saúde eficiente, que não condene aqueles impossibilitados de pagar planos de saúde a morrerem em filas de hospitais; implantar uma rede eficiente de distribuição de medicamentos, enfim,

\footnotetext{
${ }^{11}$ LACERDA, Dennis Otte. Direito da Personalidade e integridade psicofísica. XVIII Congresso Nacional do CONPEDI, 2009, São Paulo. Anais... ISBN: 978-85-7840-029-3 p.5277 - 5279.

12 Idem.

13 Idem.

14 Idem.
} 
garantir a todos seu direito constitucionalmente assegurado. Não há como falar-se em integridade psicofísica de pessoas sem direito à saúde.

\section{O stress ocupacional a luz do direito a integridade física}

Como citado anteriormente, o stress ocupacional, surge quando a demanda do trabalho excede as habilidades da pessoa e ela não consegue mais superar ou se adaptar às exigências da organização, percebidas como insuperáveis. Sendo assim, surge um desgaste anormal ou uma diminuição da capacidade da pessoa para o trabalho.

Neste contexto, Leda Maria Messias da Silva e Lory Kurahashi ${ }^{15}$, complementam dizendo que a questão de cronometrar produção ou medir a potência de um ser humano numa determinada tarefa é uma forma de pressão do capitalismo, além de deteriorar a integridade física do trabalhador, também atinge a integridade psíquica, pois a saúde mental pode ser afetada pela pressão sofrida, levando ao adoecimento. Edwin Krautler e Ivan Dias da Motta ${ }^{16}$ comentam que: "as avaliações de desempenho, com estabelecimento de metas a serem cumpridas dentro de determinado período, assim como as avaliações de potencial trazem um lado perverso, com o aumento da pressão e do stress."

As horas extras de trabalho de um obreiro quando são necessárias, são permitidas por lei, porém em demasia leva o ser humano à fadiga. Ademais, a cobrança de serviços superiores às forças do trabalhador, por vezes é o peso não da responsabilidade e cobrança pela tarefa incumbida, mais que o peso da carga em si. Outro fato é o trabalhador ter sido contratado para uma função e sempre estar sendo adequado a funções de outrem ou tarefas sem acordo prévio entre as partes, o que leva a um desvio de função. ${ }^{17}$

As autoras Leda Maria Messias da Silva e Lory Kurahashi ${ }^{18}$ afirmam que a integridade psíquica dos trabalhadores aclama por proteção, e se lesionada vem constranger a existência digna de ser humano. A liberdade em sentido lato, é ser livre de um compromisso, que no caso em discussão seria o trabalho, ou seja, quebrar a rotina de

\footnotetext{
${ }^{15}$ SILVA, Leda Maria Messias da; KURAHASHI, Lory. Os direitos de personalidade do empregado no ambiente de trabalho. XVIII Encontro Nacional do CONPEDI, 2009, Maringá. Anais... ISBN: 978-85-7840-023-1. p. 3860.

${ }^{16}$ Citado por SILVA, Leda Maria Messias da; KURAHASHI, Lory. Os direitos de personalidade do empregado no ambiente de trabalho. XVIII Encontro Nacional do CONPEDI, 2009, Maringá. Anais... ISBN: 978-85-7840-023-1 p. 3861.

${ }^{17}$ Idem.

${ }^{18}$ SILVA, Leda Maria Messias da; KURAHASHI, Lory. Os direitos de personalidade do empregado no ambiente de trabalho. XVIII Encontro Nacional do CONPEDI, 2009, Maringá. Anais... ISBN: 978-85-7840-023-1. p.3862
} 
labore, sendo por meio de descanso semanal remunerado ou por férias. O descanso não pode ser negado a um trabalhador por motivos como alegam Edwin Krautler e Ivan Dias da Motta $^{19}$, "tudo a lhe roubar momentos de lazer, os períodos de férias, o convívio com a família, o exercício da cidadania e, em última análise, a dignidade."

Leda Maria Messias da Silva ${ }^{20}$ complementa, "a todo o momento estar a incomodálo no convício com seus familiares, em horários destinados ao descaso, por meio de celular ou "bip" em atividades que não requerem tais aparatos". O descanso semanal remunerado e as férias anuais são imprescindíveis à saúde física e mental do obreiro, como a socialização e demais situações como convívio familiar.

Sendo assim, pode-se afirmar que o trabalhador não é uma máquina sem sentimentos e dores físicas, é um ser humano. Existem empregadores, que tratam o trabalhador como se o trabalho do mesmo fosse escravidão remunerada, e por outro lado, outros que pensam que o trabalho molda o caráter do ser. Tanto um como o outro moldará o caráter do ser, fixando o direito à dignidade, que se lesadas, encontram proteção jurídica, que remete à proteção do dano moral. ${ }^{21}$

Leda Maria Messias da Silva ${ }^{22}$ menciona que a previsão legal do dano moral, com o advento da Constituição de 1988, a indenização por danos morais, passou a ter relevo constitucional, especialmente no artigo 5ㅇ, incisos $\mathrm{V}$ e $\mathrm{X}$, onde ficou exposto que:

\footnotetext{
“Todos são iguais perante a lei, sem distinção de qualquer natureza, garantindo-se aos brasileiros e aos estrangeiros residentes no país a inviolabilidade dos direito à vida, à liberdade, à igualdade, à segurança e a propriedade, nos termos seguintes: (...) V - é assegurado o direito de resposta, proporcional ao agravo, além da indenização por dano material, moral ou à imagem;

(...) X - são invioláveis a intimidade, a vida privada, a honra e a imagem das pessoas, assegurando o direito à indenização pelo dano material ou moral decorrente de sua violação".
}

\footnotetext{
${ }^{19}$ KRAUTLER, Edwin; MOTTA, Ivan Dias. Os direitos da personalidade, nas relações de trabalho. Revista Jurídica Cesumar Mestrado. v.6, n.1, dez 2006. p. 506-509.

${ }^{20}$ SILVA, Leda Maria Messias da. Dano moral: direitos da personalidade e o poder diretivo do empregador. Legislação do trabalho. Revista LTr. Vol. 69, n. 04, abr. 2005. p. 421- 422. São Paulo, 2005.

${ }^{21}$ SILVA, Leda Maria Messias da; KURAHASHI, Lory. Os direitos de personalidade do empregado no ambiente de trabalho. Op. ct. p.3863.

22 SILVA, Leda Maria Messias da. Dano moral: direitos da personalidade e o poder diretivo do empregador. Legislação do trabalho. Revista LTr. Vol. 69, n. 04, abr. 2005. p. 421- 422. São Paulo, 2005.
} 
A mesma autora ainda relata que, o art. 186 do Código Civil de 2002, reafirma a possibilidade de reparação por danos morais, ao enunciar que "Aquele que, por ação ou omissão voluntária, negligência ou imprudência, violar direito e causar dano a outrem, ainda que exclusivamente moral, comete ato ilícito." $E$, nesse contexto, a recém promulgada Emenda Constitucional n. 45, que definitivamente fixou a competência da Justiça do Trabalho para "as ações de indenização por dano moral ou patrimonial, decorrentes da relação de trabalho".

Com o intuito de ilustrar uma destas ações de indenização por dano moral, decorrente da relação de trabalho, cita-se uma situação real vivida pela Caixa Econômica Federal de Maceió. A empresa foi condenada a pagar indenização por danos causados à saúde mental do seu funcionário.

De acordo com a Procuradoria Regional do Trabalho da 19a Região ${ }^{23}$, o Tribunal Regional do Trabalho - TRT da 19a Região condenou, por maioria, a Caixa Econômica Federal ao pagamento de indenização por danos morais no valor de $\mathrm{R} \$ 150$ mil reais, em favor de exempregado, afastado de suas atividades no banco devido à doença mental, adquirida devido às condições estressantes no ambiente da empresa. O TRT também determinou o pagamento integral dos valores correspondentes às despesas médico-hospitalares do exfuncionário e os gastos com medicamentos necessários ao tratamento, a partir de dezembro de 2002 até a aposentadoria por invalidez, concedida em dezembro de 2004.

Os autos do processo correu na 2a Vara do Trabalho de Maceió. De acordo com eles, o ex-empregado foi admitido pela Caixa em novembro de 1989 , para a função de escriturário. Após três anos de atividade passou a assumir atribuições de relevâncias dentro da empresa, até ser promovido a gerente, função que exerceu até ser aposentado por invalidez pelo INSS, em 2004. ${ }^{24}$

O trabalhador argumentou na peça da ação que moveu contra a Caixa que seu ambiente de trabalho passou a ser "por demais" estressantes após o lançamento do Programa de Apoio à Demissão Voluntária (PADV), em 2000. Ele sustentou ter sofrido

\footnotetext{
23 PRT - Procuradoria Regional do Trabalho. Caixa é condenada a pagar indenização por danos causados à saúde mental de trabalhador. 2009. Disponível em: <http://www.prt19.mpt.gov.br/>. Acesso em: $21 \mathrm{dez} .2010$.

${ }^{24}$ PRT - Procuradoria Regional do Trabalho. Caixa é condenada a pagar indenização por danos causados à saúde mental de trabalhador. 2009. Disponível em: <http://www.prt19.mpt.gov.br/>. Acesso em: $21 \mathrm{dez} .2010$.
} 
pressão psicológica pelo banco, o que provocou danos a sua saúde. As afirmações do exfuncionário sobre a fixação de metas e cobranças foram confirmadas por testemunhas. ${ }^{25}$

Diante disto, verifica-se o clima de tensão existente na empresa. Clima esse que pode desencadear uma série de conseqüências desagradáveis aos trabalhadores.

Leda Maria Messias da Silva ${ }^{26}$ comenta que, "a indenização pecuniária jamais seria suficiente para o ressarcimento integral ou jamais restabeleceria o status quo ante, mas ao menos serviria como lenitivo ao lesionado". Afinal, o homem é um ser titular de direitos, e o Código Civil de 2002, têm como principal a dignidade da pessoa humana.

\section{Conclusão}

O presente estudo possibilitou analisar os direitos da personalidade e o princípio da dignidade humana da pessoa como empregado, relacionando-o com o stress na sua integridade física.

Verificou-se que a Constituição Federal de 1988 plasmou, à guisa de fundamento da República Federativa do Brasil como Estado Democrático de Direito, a dignidade da pessoa humana, retratando o reconhecimento de que o indivíduo há de constituir o objetivo primacial da ordem jurídica. Através do estudo da flexibilização das normas trabalhistas, conclui-se que o trabalhador ainda precisa de leis que assegurem condições dignas de trabalho para não ver derrubados todos os direitos trabalhistas já conquistados. Não se pode banalizar a negociação que diminua os direitos sociais mínimos, pois isso demonstraria uma injusta vitória do capitalismo sobre o trabalho digno.

Em relação ao stress que compromete a integridade física do indivíduo, conclui-se que é necessário que a estruturação do ambiente de trabalho atenda às exigências adequadas ao bom desempenho do trabalhador, preservando a sua integridade. Nem sempre o caminho é fácil, pelo contrário, é longo e as mudanças continuarão sendo as mais difíceis, pois há muito tempo vem se tentando humanizar o ambiente ocupacional, sabendo que há uma grande complexidade, exigindo abordagens inovadoras, criativas, com base técnico-científicas.

\section{Referências}

\footnotetext{
${ }^{25}$ Idem.

${ }^{26}$ SILVA, Leda Maria Messias da. Dano moral: direitos da personalidade e o poder diretivo do empregador. Legislação do trabalho. Revista LTr. Vol. 69, n. 04, abr. 2005. p. 421- 422. São Paulo, 2005.
} 
ALMEIDA, Edvaldo Nilo de. Repensando os princípios: princípios constitucionais sociais trabalhistas e a mudança dos paradigmas dos princípios específicos do direito do trabalho. Revista LTr, São Paulo, ano 68-04, p. 450-466, abr. 2004.

ALVES, G. Luiz B. Stress - diagnóstico e tratamento. Curitiba: Relisul, 1992.

BETIOLI, Antonio Bento. Introdução ao direito: lições de propedêutica jurídica tridimensional. São Paulo: Letras \& Letras, 2004.

CABRAL, A. P. T. et al. O estresse e as doenças psicossomáticas. 2001 Revista de Psicologia. Disponível em: < http://www.icb.ufmg.br/lpf>. Acesso em: 04 de out. 2007.

CAMPANA, Priscila. O impacto do neoliberalismo no direito do trabalho: desregulamentação e retrocesso histórico. Revista de Informação Legislativa, Brasília - DF, ano 37, n. 147, p. 129-144, jul./set. 2000.

CUPIS, Adriano de. Os direitos da personalidade. São Paulo: Livraria Morais, 2006.

DINIZ, Maria Helena. Curso Direito do Trabalho. São Paulo, 2006

FRANCO FILHO, Georgenor de Sousa. Globalização e desemprego: Mudanças nas relações de trabalho. São Paulo: Ltr, 1998.

KRAUTLER, Edwin; MOTTA, Ivan Dias. Os direitos da personalidade, nas relações de trabalho. Revista Jurídica Cesumar Mestrado. V. 6, n. 1, dez. 2006.

LACERDA, Dennis Otte. Direito da Personalidade e integridade psicofísica. XVIII CONGRESSO NACIONAL DO CONPEDI, 2009, São Paulo. Anais... ISBN: 978-85-7840-029-3

LEITE, Rita de Cássia Curvo. Transplantes de órgãos e tecidos e os direitos da personalidade. São Paulo, 2006.

LOPES, Otávio Brito. Flexibilização do direito do trabalho. Um bem ou um mal? Revista Jurídica Consulex, Brasília, ano VI, n. 123, fev. 2002.

LOTUFO, Renan. Código Civil comentado. Rio de Janeiro, 2005

MARTINS, Sérgio Pinto. Direito do trabalho. São Paulo: Atlas S.A, 2002.

MELLER, Fernanda; SILVA, Gilson Hugo Rodrigo. A flexibilização das normas trabalhistas como uma tendência atual e a integridade física do trabalhador como aspecto fundamental da personalidade. Revista de Ciências Jurídicas - UEM. v.5, n.1, jan/jun 2007.

MENDES, Ana Magnólia; TAMAYO, Álvaro. Valores organizacionais e prazer sofrimento no trabalho. PsicoUSF. Jun. 2001, vol.6, no.1, p.39-46. Disponível em: <http://www.scielopsi.bvs.br.> Acesso em: 28 de set. 2007.

NASCIMENTO, Amauri Mascaro. Curso de Direito do Trabalho. São Paulo : LTr, 1997. 
PASCHOAL, Tatiane e TAMAYO, Alvaro. Validação da escala de estresse no trabalho. Universidade de Brasilia. São Paulo: Casa do Psicólogo. Estudos de Psicologia 2004, 9(1), 45-52. Disponível em: <http://www.scielo.br/pdf/epsic/v9n1/22380.pdf.> Acesso em: 20 dez 2010.

PRT - Procuradoria Regional do Trabalho. Caixa é condenada a pagar indenização por danos causados à saúde mental de trabalhador. 2009. Disponível em:

<http://www.prt19.mpt.gov.br/>. Acesso em: 21 dez. 2010.

SOUZA, Capelo de. O direito geral da personalidade. São Paulo, 2008.

SILVA, Leda Maria Messias da. Ambiente de trabalho digno e a responsabilidade da empresa na questão dos direitos de personalidade dos empregados. Revista de Ciências Jurídicas Uem, Maringá, v.6, n.1, jan/jun 2008.

SILVA, Leda Maria Messias da; KURAHASHI, Lory. Os direitos de personalidade do empregado no ambiente de trabalho. XVIII ENCONTRO NACIONAL DO CONPEDI, 2009, Maringá. Anais... ISBN: 978-85-7840-023-1.

SILVA, Leda Maria Messias da. O cumprimento da função social no tocante ao meio ambiente de trabalho. Revista Jurídica Cesumar Mestrado, Maringá, V. 8 n.1 (jan./jun. 2008). Maringá, PR: CUM, 2008.

SILVA, Leda Maria Messias da. Ambiente de trabalho digno e a responsabilidade da empresa na questão dos direitos de personalidade dos empregados. Revista de Ciências Jurídicas UEM, Maringá, v .6, n.1, jan/jun 2008.

SILVA, Leda Maria Messias da. Dano moral: direitos da personalidade e o poder diretivo do empregador. Legislação do trabalho. Revista LTr. Vol. 69, n. 04, abr. 2005. p. 421- 422. São Paulo, 2005.

SOARES, Fernanda Heloisa Macedo; MASSINE, Maiara Cristina Lima. A flexibilização do direito do trabalho e a constituição federal de 1988. In: XIX ENCONTRO NACIONAL DO CONPEDI, 2010, Fortaleza. Anais... ISBN: 978-85-7840-023-1.

SÜSSEKIND, Arnaldo. Direito constitucional do trabalho. Rio de Janeiro: Renovar, 2001.

VILLALLOBOS, J. O. Estrés y trabajo. Instituto Mexicano del Seguro Social. México, 1999. Medspain. Disponível: <http://www.medspain.com/n3_feb99/stress.htm> Acesso em: 22 nov. 2010. 
Artigo recebido em:

08 de abril de 2011.

Artigo aprovado em: 30 de abril de 2011. 